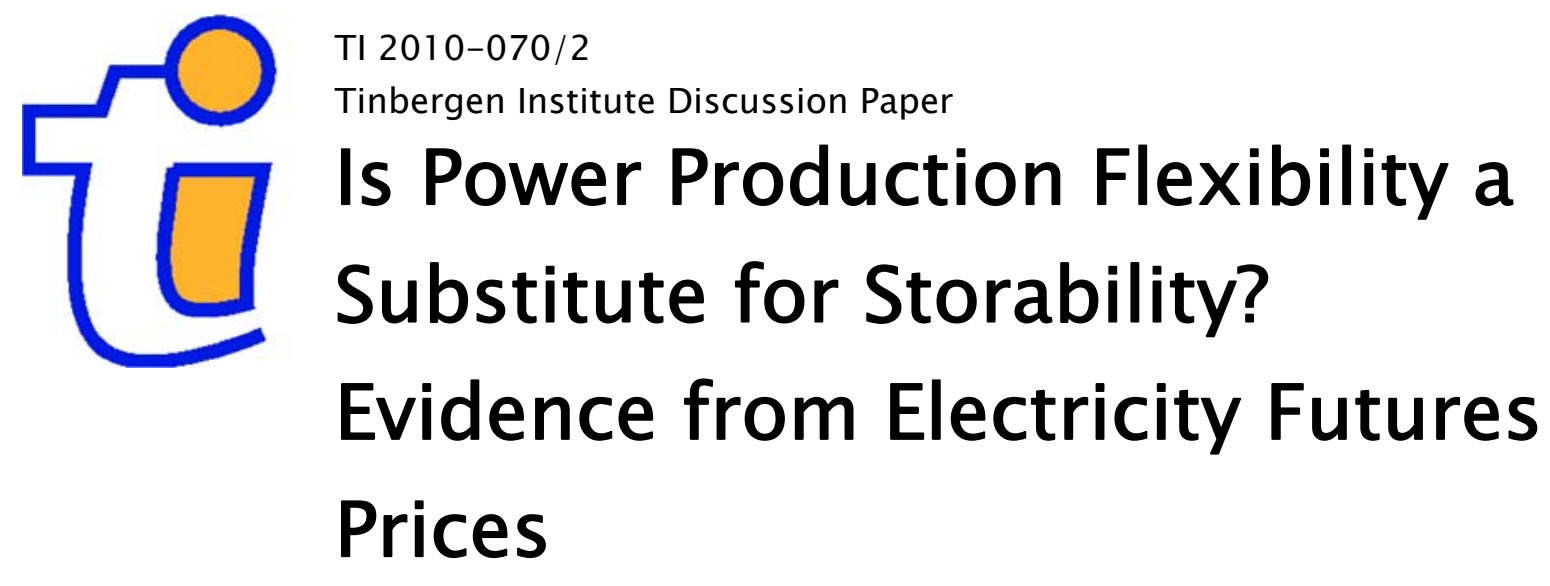

Ronald Huisman

Mehtap Kilic*

Erasmus School of Economics, Erasmus University Rotterdam.

* Timbergen Institute 


\title{
Is power production flexibility a substitute for storability? Evidence from electricity futures prices.
}

\author{
Ronald Huisman, Mehtap Kilic \\ Erasmus School of Economics, Erasmus University Rotterdam ${ }^{1}$
}

July 2010

\begin{abstract}
Electricity is not storable. As a consequence, electricity demand and supply need to be in balance at any moment in time as a shortage in production volume cannot be compensated with supply from inventories. However, if the installed power supply capacity is very flexible, variation in demand can be counterbalanced with flexible adjustment of production volumes. Therefore, supply flexibility can replace the role of inventory. In this paper, we question whether power production flexibility is a substitute for storability. To do so, we examine power futures prices from countries that differ in their power supply and test whether power futures prices contain information about expected future spot prices and risk premiums and examine whether futures prices from a market in which power supply is more flexible would lead to futures prices that are more in line with the theory of storage. We find the opposite; futures prices from markets with flexible power supply behave according to the expectations theory. The implicit view from futures prices is that flexibility is not a substitute for storability.
\end{abstract}

Keywords: Electricity futures prices; forward risk premium; theory of storage, expectations theory

\footnotetext{
${ }^{1}$ Erasmus School of Economics, Erasmus University Rotterdam, P.O. Box 1738, 3000 DR, Rotterdam. Tel: +31 104088932 .

Respective email addresses are: rhuisman@ese.eur.nl and kilic@ese.eur.nl.
} 


\section{Introduction}

Prices in liberalized power markets fluctuate heavily. The most evident features of electricity price dynamics are the presence of a seasonality, meanreversion, time-varying volatility and price spikes ${ }^{1}$. These characteristics of electricity prices can be attributed to the convex supply curve and - in the short run - price-inelastic demand (Redl et al. [2009]) and non-storability of electricity. Supply or demand shocks, such as unexpected outages of generation units, transmission capacities or weather change, cannot be compensated by additional supply from inventories. As a consequence, electricity demand and supply need to be in balance at any moment in time. If there is an imbalance, sudden jumps in electricity prices may occur, especially in those periods where demand is high or - alternatively stated - where reserve capacity is low (Mount et al. [2006] and Huisman [2008]).

Although electricity is not directly storable, it's indirectly storable. If the installed power supply capacity is very flexible, variation in demand can be counterbalanced with flexible adjustment of production volumes. Therefore, supply flexibility can replace the role of inventory to some extend. A hydro power plant is in effect a big inventory of water that can be converted quite flexibly into power at any moment in time. The difference between flexibility and storability also becomes apparent, as the capacity of the hydro power plant depends on the amount of water in the basin, which is uncertain and seasonal due to rainfall conditions. Storability means that it is possible to have a good in store such that one knows the price and the quality of the good. Flexibility means that we can produce the good in no time quickly responding to variation in demand and supply, but one doesn't know the exact price and capacity with which the substitute good can be converted in the good needed (especially in the long run). Although storability is different from flexibility, it fulfills an important function as flexibility makes it possible to counterbalance temporary differences between demand and supply volumes.

In this paper, we question to what extend power production flexibility is a substitute for storability. To do so, we examine power futures prices from countries that differ in their power supply and test whether more futures prices from a market with more flexible power supply makes power futures prices behave more in accordance with the theory of storage. According to this theory, the forward price of a commodity depends on the current spot

\footnotetext{
${ }^{1}$ For an overview of the characteristics of electricity price dynamics we refer to Eydeland and Wolyniec [2003], Pilipovic [2007], and Huisman [2009].
} 
price, the interest rate, storage costs, and the convenience yield. If storability is not possible, or if the underlying good is subject to deterioration, or if storage is costly in relation to the value of the good, then the theory of storage does not apply and forward prices behave according to the expectations theory: the forward price of a good depends on the expected spot price of the good during the delivery period plus a risk premium. As Fama and French [1987] note, these theories are not per definition mutually exclusive as, for instance, convenience yields reflect expectations as well. In case of electricity as the underlying good, the theory of storage cannot apply, but perhaps only in the case of indirect storage in the form of supply flexibility. We therefore test empirically whether power futures prices contain information about expected future spot prices and risk premiums and examine whether futures prices from a market in which power supply is more flexible would lead to futures prices that are more in line with the theory of storage. We find the opposite; futures prices from markets with flexible power supply behave according to the expectations theory. The implicit view from futures prices is that flexibility is not a substitute for storability.

The plan of the paper is as follows. Section 2 reviews the literature on storability and forward prices. Section 3 discusses the methodology that we apply. Section 4 provides information on the data. Section 5 shows the results and section 6 concludes.

\section{Storability and forward prices}

For hedging this exposure to price risk, long-term contracts like forwards and futures, gained increased interest for agents. Therefore we can state that the non-storability of electricity has important implications on the valuation of forward contracts. The study of the relationship between forward and spot prices has been the main topic of many theoretical and empirical papers. For storable commodities, the theory of storage explains the difference between contemporaneous spot and forward prices in terms of interest forgone in storing a commodity, warehousing costs, and a convenience yield on inventory. Nevertheless, in the electricity market the theory of storage cannot be applied due to the fact that electricity cannot be stored or at least not efficiently. Therefore, another general approach to price forward contracts is used in the literature as an alternative, which is called the expectations theory. According to this theory, electricity forward prices can be split into two components: a forecast for the future spot price during the delivery period and an expected risk premium (see, for example Breeden [1980], Hazuka [1984] and Fama and French [1987]). Among many others, Fama and French [1987] describe how traders valuate a forward contract 
in case of storability of the underlying commodity (theory of storage) and the valuation of a forward contract in case if non or limited storability of the underlying good (expectations theory). According to the expectations theory forward prices for non-storable commodities reflect the expectation of market participants on the (average) spot price in the delivery period and a risk premium that compensates producers for bearing the uncertainty of committing to sell against fixed prices.

Several studies have examined the empirical relationship between electricity forward prices and expected spot prices to identify the electricity risk premium. Bessembinder and Lemmon [2002] studied the forward risk premium in the electricity prices by using an equilibrium model. In this equilibrium model the forward risk premium is negatively related to the variance, but positively related to the skewness of spot prices. Longstaff and Wang [2004] conduct an empirical analysis of the forward risk premium by using hourly prices. They state that these risk premiums are time varying and directly related to economic risk factors, such as the volatility of unexpected changes in demand, spot prices, total revenues and the risk that the electricity transmission system reaches its capacity limit. These findings are consistent with Bessembinder and Lemmon [2002]. Douglas and Popova [2008] and van Treslong and Huisman [2010] relate forward prices to indirect storability as they show that higher natural gas inventory levels reduces the forward risk premium in the PJM market, especially during extremely warm and cold periods. These studies analyze so called day-ahead prices which in effect - are one-day futures prices; prices from electricity futures contracts that deliver in one specific hour in the next day. Others focused on longer delivery periods and time to maturity. Furio and Meneu [2010] investigate the Spanish electricity market for long-term forward risk premiums, using both an ex-ante and ex-post approach. For month delivery future contracts, they conclude that the ex-post risk premium is negative but not statistically significant and that the ex-ante risk premium is positive. One of the first researches about the risk premium on the German EEX market is conducted by Wilkens and Wimschulte [2007]. For future contracts with a time to maturity up to six months they find positive risk premiums. The observed risk premiums are highly volatile and change regularly in sign. Kolos and Ronn [2008] confirms this result as they find positive risk premiums for the EEX market as well. Several recent studies examine the risk premium in the Nordic market. Gjolberg and Johnsen [2001] and Botterud et al. [2002] identify positive risk premiums in the Nordic market for futures with a time to maturity up to one year. Lucia and Torró [2008] find significant positive risk premiums for using weekly electricity futures contracts from the NPX. Weron [2008] determines the market price risk in the NPX futures market 
using stochastic models. He finds decreasing risk premiums with increasing time to maturity.

The consensus view is that electricity is a non-storable commodity and therefore electricity forward prices behave according to the expectations theory. Electricity forward prices reflect expected (average) spot prices during the delivery period and an ex-ante - positive time-varying risk premium which size relates to anticipated variance and skewness in spot prices. Although electricity is non-storable, it's at least indirectly storable and if electricity supply would be extremely flexible, this flexibility could be a substitute for storability to some extend. The influence of flexibility on risk premiums is observed by Douglas and Popova [2008] and van Treslong and Huisman [2010] who show that higher gas inventory levels reduce the risk premium. Higher gas inventory levels reflect more flexibility in the sense that their is more capacity to convert gas in power. If flexibility is a substitute for storability, then electricity forward prices should behave in line with the theory of storage instead of the expectations theory. This paper aims to shed some light on this issue.

\section{Methodology}

The goal of this paper is to examine to what extend flexibility is a substitute for storability. As we discussed that commodity forward contracts are priced based on the efficiency with which the commodity can be stored, we therefore expect that if flexibility is a substitute for storability, forward prices from markets with flexible production should be in line with the theory of storage. We collected electricity day-ahead and futures prices from Belgium, Germany, The Netherlands, and NordPool ${ }^{2}$. Table 1 provides and overview of the type of production of electricity used in 2007 for each country. The Nordic market relies heavily (53\% of total production in 2007) on Norwegian and Swedish hydropower plants which are connected with mountain reservoirs. Short-term storage is also available by hydro-pumped storage facilities (Fleten and Lemming [2003]). Because of the indirect storage capability producers have production flexibility and therefore can benefit from varying electricity prices and produce little when prices are low and produce with full capacity when the prices are high (Fleten and Lemming [2003]). While the NordPool markets produce most of their electricity with flexible hydropower, the other countries predominant power sources rely heavily on fossil fuels such as coal (Germany $49 \%$ in 2007), natural gas (the Netherlands - 57\% in 2007), and nuclear (Belgium - 54\% in 2007). From this, we conclude that the Nordic countries have the most flexible power supply

\footnotetext{
${ }^{2}$ The pooled electricity market from the Nordic European countries.
} 
Table 1: Electricity generation by source in 2007 (\%).

\begin{tabular}{|l|cccc|} 
Fuel & Netherlands & Belgium & Germany & NordPool \\
\hline Nuclear & 4 & 54 & 22 & 22 \\
Hydro & 0 & 2 & 4 & 53 \\
Coal & 28 & 9 & 49 & 11 \\
Gas & 57 & 29 & 11 & 5 \\
Other & 11 & 6 & 13 & 9
\end{tabular}

compared with the other countries in our sample.

In order to examine to what extend flexibility is a substitute for storability, we examine the futures prices from the four markets in our sample. In case flexibility is indeed a substitute for storability, Nordic futures prices should behave in line with the theory of storage. To examine this, we follow Fama and French [1987], who analyze the applicability of the theory of storage and the expectation theory for various commodity forward prices. Their approach is based on Fama [1984], who analyzed the forward premium in foreign exchange rate futures contracts by decomposing this into the expected rate of change and a risk premium. The following summarizes the methodology of Fama [1984] and Fama and French [1987] as we apply the same method for the futures prices from the four power markets in our sample.

Let $F(t, T)$ be the forward price per MWh quoted at time $t$ for the delivery of $1 \mathrm{MW}$ of electricity in each hour during the delivery period $T$ $(t<T) . S(t)$ is the day-ahead price per MWh quoted on day $t$ for delivery of $1 \mathrm{MW}$ of electricity in each hour of the day $t+1^{3}$. The future expected spot price $E_{t}[S(T)]$ is the average day-ahead price during the future delivery period $T$, subject to information sets available to market participants at time $t . E_{t}[P(t, T)]$ is the expected risk premium per MWh for delivery of electricity in period $T$ quoted at time $t$. Under the expectations theory, the forward price quoted at time $t$ consists of an expected risk premium and a forecast of a future spot price:

\footnotetext{
${ }^{3}$ We therefore implicitly assume that the day-ahead price is the best proxy for the spot price. This is not necessarily true as many countries have real-time markets in which electricity can be traded on the same day as it is delivered. These markets are less liquid, however, due to the fact that only the most flexible power plants can reschedule their production volume flexible enough to purchase and sell on the real-time market. To circumvent this liquidity issue, we have chosen for the day-ahead price as the proxy for the spot price.
} 


$$
F(t, T)=E_{t}[S(T)]+E_{t}[P(t, T)] .
$$

Fama and French [1987] proceed with subtracting the current spot price from both sides in the equation:

$$
F(t, T)-S(t)=E_{t}[P(t, T)]+E_{t}[S(T)-S(t)] .
$$

From equation 1 we have that the expected risk premium equals the difference between the forward price and the forecast of the future spot price:

$$
E_{t}[P(t, T)]=F(t, T)-E_{t}[S(T)] .
$$

Substituting equation 3 into 2, yields:

$$
F(t, T)-S(t)=E_{t}[S(T)-S(t)]+F(t, T)-E_{t}[S(T)] .
$$

Equation 4 shows that the forward basis, $F(t, T)-S(t)$, observed at time $t$ contains information about the expected change in the spot price between $t$ and $T$ and the expected to be realized risk premium. To test for time varying risk premiums and price forecasts in commodity forward prices, Fama and French [1987] consider the following regressions, as proposed by Fama [1984], of the change in the spot price and the risk premium on the observed basis:

$$
S(T)-S(t)=\alpha_{1}+\beta_{1}[F(t, T)-S(t)]+\sigma_{1} \epsilon_{1, t},
$$

and

$$
F(t, T)-S(T)=\alpha_{2}+\beta_{2}[F(t, T)-S(t)]+\sigma_{2} \epsilon_{2, t} .
$$

Fama and French [1987] show that the basis $F(t, T)-S(t)$ has reliable information about the future change in the spot price, i.e. a positive estimated value for $\beta_{1}$ for eight commodities. Five of these (broilers, eggs, hogs, oats, cattle, and pork bellies) are animal products, whose bulk and perishability imply high storage costs (relative to value). The other three commodities (oats, soy beans, and soy meal) also have high storage costs relative to value. For gold and platinum, whose storage costs are low relative to value, forward prices do not exhibit forecast power $\beta_{1}$ is not significantly different from zero. Commodities, such as lumber, soy oil, cocoa, corn, and wheat, have significant expected risk premiums, i.e. their estimates for $\beta_{2}$ are significantly different from zero. Forward prices from orange juice and plywood exhibit both forecasting power and risk premiums. For the first set of commodities, storage is costly and the goods deteriorate over time, whereas storage costs and deterioration are of lesser importance for the second set of commodities. It's therefore likely that the theory of storage 
explains the forward prices of the second group better; their forward prices reflect the current spot price and (time-varying) risk premium factors such as interest rates, storage costs, and convenience yields, but do not contain information about future spot price changes. This is in line with positive estimates for $\beta_{2}$ and not significant estimates for $\beta_{1}$, because if the latter would be significant, the forward basis would contain information about expected spot price changes.

In this paper, we apply the same methodology to electricity futures prices from Belgium, Germany, the Netherlands, and NordPool. As the latter market is more based on flexible production than the other three, we would expect that the estimates for $\beta_{1}$ are zero and for $\beta_{2}$ are close to one for the NordPool futures under the assumption that flexibility is a substitute for storability (such that the theory of storage holds for flexible power supply). For the other markets which are less flexible in their power supply, we expect the expectation theory to hold (such that the forward price consists of an expectation and a risk premium) and that we find positive values for both $\beta_{1}$ and $\beta_{2}$.

\section{Data and descriptive analysis}

The primary data for this study consists of average day-ahead electricity prices for four markets, the Amsterdam Power Exchange (APX), the Belgian Power Exchange (BELPEX), the European Energy Exchange (EEX) and the Nordic Power Exchange (NordPool), which is the single power market for Norway, Denmark, Sweden and Finland. The futures contracts include the month delivery baseload contracts ${ }^{4}$ from one month through six months to maturity. The dataset consists of the first trading day of the month closing price observations from 5 January 2004 through 2 June 2008, having 54 monthly futures price observations for the Dutch ENDEX market. The Belgian Power Exchange (BELPEX) is an hourly day-ahead spot market, but has only been trading since late November 2006. Before November 2006 Belgium had no organized market. In the absence of an exchange, Electrabel published the Belgian Power Index (BPI), which allowed participants to buy and sell day-ahead base-load power in blocks. For the Belgian ENDEX futures market the sample period is from 1 October 2004 through 2 June 2008, having 45 monthly futures price observations. For the EEX market the sample period is from 3 February 2003 through 2 June 2008, having 65 monthly futures price observations and the sample period for NPX (Eltermin) market is from 4 April 2005 through 2 June 2008, having 39 monthly futures price observations. To estimate the parameters in equation 5 and 6

\footnotetext{
${ }^{4}$ Delivering $1 \mathrm{MW}$ of power in any hour of a specific month.
} 
we analyze the futures contracts that have a delivery period of one month, therefore we use a proxy for the spot price at $T$, by taking the average dayahead price in the delivery month. All prices are measured in natural logs.

In order to assess whether the regressions 5 and 6 can reliably assign basis variation to the expected premiums or expected spot price changes, we examine the standard deviations of the basis, the change in the spot price, and the risk premium for the different markets and different contract maturities. Table 2 shows that the standard deviation of the basis does not differ from the standard deviation of the change in the spot price and the standard deviation of the risk premium for all markets and maturities, indicating that estimation results will not be influenced by significant differences in variance between the dependent and independent variables.

Table 2: Standard deviations of the basis, the spot price change, and the risk premium.

\begin{tabular}{|l|c|c|c|c|} 
Market & Maturity & $\begin{array}{c}F(t, T)-S(t) \\
\text { Basis }\end{array}$ & $\begin{array}{c}S(T)-S(t) \\
\text { Change }\end{array}$ & $\begin{array}{c}F(t, T)-S(T) \\
\text { Premium }\end{array}$ \\
\hline \hline APX & M1 & 0.312 & 0.342 & 0.272 \\
APX & M2 & 0.329 & 0.396 & 0.314 \\
APX & M3 & 0.346 & 0.389 & 0.321 \\
APX & M4 & 0.376 & 0.417 & 0.337 \\
APX & M5 & 0.398 & 0.471 & 0.347 \\
APX & M6 & 0.388 & 0.496 & 0.378 \\
BELPEX & M1 & 0.341 & 0.364 & 0.297 \\
BELPEX & M2 & 0.364 & 0.433 & 0.344 \\
BELPEX & M3 & 0.410 & 0.495 & 0.369 \\
EEX & M1 & 0.277 & 0.297 & 0.240 \\
EEX & M2 & 0.304 & 0.347 & 0.278 \\
EEX & M3 & 0.308 & 0.332 & 0.286 \\
EEX & M4 & 0.309 & 0.337 & 0.286 \\
EEX & M5 & 0.323 & 0.359 & 0.295 \\
EEX & M6 & 0.320 & 0.378 & 0.297 \\
NPX & M1 & 0.144 & 0.251 & 0.210 \\
NPX & M2 & 0.180 & 0.330 & 0.273 \\
NPX & M3 & 0.230 & 0.401 & 0.338 \\
NPX & M4 & 0.261 & 0.461 & 0.601 \\
NPX & M5 & 0.280 & 0.500 & 0.400 \\
NPX & M6 & 0.287 & 0.503 & 0.400 \\
\hline \hline
\end{tabular}

Table 2 reveals other insight as well. Variation in the basis is generated by variation in short-term demand and supply and the flexibility with which power supply volumes can be adjusted to absorb shocks in demand and supply. For NPX, standard deviation of the basis is lower than for the other three power markets. This can be explained by hydropower, which ensures 
the flexibility of production in the Nordic market. For all markets, the basis standard deviations increase drastically with time to maturity, especially for the NPX market due to apparent seasonality (see Lucia and Schwartz [2002]). The increase of the standard deviation of the basis for NPX is due to seasonality, which is an essential characteristic of electricity prices in the Nordic markets. Seasonality in NPX electricity prices occur because of the forces on both supply and demand in summertime and wintertime. In summertime melting snow and autumn rains increase the level of inflow in the reservoirs of the hydro-power plants. The capacity of the reservoirs is constrained and this has influence on the production level. Low demand and high supply will cause a downward pressure on the power price in the summer. In wintertime high demand for heating purposes will cause an upward pressure on the price. This increase is less severe for APX, BELPEX and EEX.

From table 2, we furthermore observe that the standard deviation of the risk premium increases with time to maturity for all markets reflecting increased uncertainty when maturity is further away in the future.

\section{Results}

Table 3 reports the estimates of the parameters in the spot price change regression 5 and the risk premium regression 6. For APX, EEX and NPX the results of the futures contracts with one until six months to maturity (M1-M6) and for BELPEX the results of the one to three months to maturity (M1-M3) contracts are shown.

Focusing on the M1 (next month delivery) results, the $\beta_{1}$ estimates are positive and significantly different from zero at the 99-percentage confidence level, which implies that the basis contains reliable information about future spot price changes. The $\beta_{1}$ estimates range between 0.69 and 0.72 for the Belgium, Dutch, and German markets. For the NPX, the estimate for $\beta_{1}$ is higher and almost equal to one at 0.96 . The $\beta_{2}$ estimated are positive and significant, ranging between 0.28 and 0.31 , for the Belgium, Dutch, and German futures prices and is 0.04 and not significant for the Nordic futures prices. Evidence for time-varying risk premiums is found for the first three markets, but not for the Nordic market. In terminology of Fama and French [1987], Nordic futures prices are of type SF (strong forecast power) who have reliable forecast power and no evidence for time-varying risk premiums. Fama and French [1987] show that broilers, eggs, hogs, and oats are of this type. For the other markets, the futures prices are of type FESP (fore- 
Table 3: Regressions of the spot price change 5 and the risk premium 6 on the basis.

\begin{tabular}{|c|c|c|c|c|c|c|c|c|}
\hline M1 & Max. & Obs. & $\beta_{1}$ & $\beta_{2}$ & $\mathbf{t}\left(\beta_{1}\right)$ & $\mathbf{t}\left(\beta_{2}\right)$ & $\overline{R_{1}^{2}}$ & $R_{2}^{2}$ \\
\hline APX & 54 & 54 & 0.72 & 0.28 & $5.50^{* * *}$ & $2.12^{* *}$ & 0.43 & 0.10 \\
\hline BELPEX & 45 & 45 & 0.69 & 0.31 & $5.78^{* * *}$ & $2.55^{* *}$ & 0.42 & 0.12 \\
\hline EEX & 65 & 65 & 0.70 & 0.30 & $6.12^{* * *}$ & $2.62^{* *}$ & 0.43 & 0.12 \\
\hline NPX & 39 & 39 & 0.96 & 0.04 & $4.04^{* * *}$ & 0.14 & 0.30 & 0.00 \\
\hline M2 & Max. & Obs. & $\beta_{1}$ & $\beta_{2}$ & $\overline{\mathbf{t}\left(\beta_{1}\right)}$ & $\overline{\mathbf{t}\left(\beta_{2}\right)}$ & $R_{1}^{2}$ & $R_{2}^{2}$ \\
\hline APX & 54 & 54 & 0.76 & 0.23 & $5.22^{* * *}$ & 1.60 & 0.41 & 0.06 \\
\hline BELPEX & 45 & 45 & 0.77 & 0.23 & $5.07 * * *$ & 1.53 & 0.41 & 0.06 \\
\hline EEX & 65 & 65 & 0.73 & 0.27 & $4.74^{* * *}$ & $1.72^{*}$ & 0.41 & 0.09 \\
\hline NPX & 39 & 39 & 1.04 & -0.04 & $3.64^{* * *}$ & -0.16 & 0.32 & 0.00 \\
\hline M3 & Max. & Obs. & $\beta_{1}$ & $\beta_{2}$ & $\mathbf{t}\left(\beta_{1}\right)$ & $\mathbf{t}\left(\beta_{2}\right)$ & $R_{1}^{2}$ & $R_{2}^{2}$ \\
\hline APX & 54 & 54 & 0.70 & 0.30 & $5.33^{* * *}$ & $2.22^{* *}$ & 0.39 & 0.10 \\
\hline BELPEX & 45 & 30 & 0.82 & 0.18 & $4.63^{* * *}$ & 1.00 & 0.46 & 0.04 \\
\hline EEX & 65 & 65 & 0.65 & 0.35 & $3.61^{* * *}$ & $1.95^{*}$ & 0.36 & 0.14 \\
\hline NPX & 39 & 39 & 0.94 & 0.06 & $4.05^{* * *}$ & 0.27 & 0.29 & 0.00 \\
\hline M4 & Max. & Obs. & $\beta_{1}$ & $\beta_{2}$ & $\mathbf{t}\left(\beta_{1}\right)$ & $\mathbf{t}\left(\beta_{2}\right)$ & $R_{1}^{2}$ & $R_{2}^{2}$ \\
\hline APX & 54 & 48 & 0.74 & 0.26 & $6.42^{* * *}$ & $2.29^{* *}$ & 0.44 & 0.09 \\
\hline BELPEX & 45 & - & - & - & - & - & - & - \\
\hline EEX & 65 & 65 & 0.67 & 0.33 & $3.96^{* * *}$ & $1.99 *$ & 0.37 & 0.13 \\
\hline NPX & 39 & 39 & 1.04 & -0.04 & $5.67^{* * *}$ & -0.24 & 0.35 & 0.00 \\
\hline M5 & Max. & Obs. & $\beta_{1}$ & $\beta_{2}$ & $\mathbf{t}\left(\beta_{1}\right)$ & $\mathbf{t}\left(\beta_{2}\right)$ & $R_{1}^{2}$ & $R_{2}^{2}$ \\
\hline APX & 54 & 48 & 0.82 & 0.18 & $8.45^{* * *}$ & $1.83^{*}$ & 0.50 & 0.04 \\
\hline BELPEX & 45 & - & - & - & - & - & - & - \\
\hline EEX & 65 & 65 & 0.70 & 0.30 & $4.61^{* * *}$ & $1.99 *$ & 0.40 & 0.11 \\
\hline NPX & 39 & 39 & 1.08 & -0.08 & 5.20 *** & -0.37 & 0.37 & 0.00 \\
\hline M6 & Max. & Obs. & $\beta_{1}$ & $\beta_{2}$ & $\mathbf{t}\left(\beta_{1}\right)$ & $\mathbf{t}\left(\beta_{2}\right)$ & $R_{1}^{2}$ & $R_{2}^{2}$ \\
\hline APX & 54 & 48 & 0.83 & 0.17 & $7.61^{* * *}$ & 1.53 & 0.45 & 0.03 \\
\hline BELPEX & 45 & - & - & - & - & - & - & - \\
\hline EEX & 65 & 65 & 0.77 & 0.23 & $6.12^{* * *}$ & $1.88^{*}$ & 0.42 & 0.06 \\
\hline NPX & 39 & 39 & 1.07 & -0.07 & $4.16^{* * *}$ & -0.25 & 0.37 & 0.00 \\
\hline
\end{tabular}

The t-statistics, $\mathrm{t}\left(\beta_{1}\right)$ and $\mathrm{t}\left(\beta_{2}\right)$, are based on robust Newey-West Heteroskedasticity and Autocorrelation (HAC) standard errors. $* * *, * *, *$, denote a test statistic is statistically significant at the $1 \%, 5 \%$ or $10 \%$ level of significance. $R_{1}^{2}$ and $R_{2}^{2}$ are the coefficients of determination for the change and premium regressions, respectively. Obs. is the number of observations in a regression, and Max. is the number of months in the sample period. 
cast power and expected premiums), being in the same category as orange juice and plywood as found by Fama and French [1987]. These results are the same for all maturities.

The results indicate that power futures prices contain reliable information about future spot price changes. However, the results over the different markets differ in terms of expected risk premiums. The futures prices from the market with flexible production (NPX) shows no evidence for timevarying risk premiums whereas the prices from the other markets do. The first conclusion that we draw from these results is that flexibility is not per definition a substitute for storability. If it was, the futures prices for the NPX should contain no information about future spot prices and $\beta_{1}$ would have been zero. In contrast, their $\beta_{1}$ estimates are higher than for the other markets and close to one. This result can be explained by noticing that, although production is flexible, the supply capacity is subject to seasonal variation as it is for the animal commodities that are of type $S F$ such as broilers, eggs, and hogs. Hydropower is flexible enough to absorb short term changes in demand and supply, but supply capacity and therefore storage costs (as it were) is too uncertain in the long run. For the other markets, supply capacity is less subjective to seasonality.

The coefficients of determination $\left(R_{1}^{2}\right)$ in the spot price change regression 5 are around $40 \%$ for APX, BELPEX and EEX and $30 \%$ percent for NPX, throughout all contract maturities. This is higher than the statistical power of the regression outcomes reported in Fama and French [1987]. The coefficients of determination $\left(R_{1}^{2}\right)$ for the risk premium regression 6 are much lower for all four electricity markets during all contract maturities. Variation in the basis explains changes in the future spot price of electricity better than changes in the expected risk premium.

It is worth noting that the absence of evidence for time-varying risk premiums in the the Nordic market does not imply that risk premiums in that market are zero as stated by Fama and French [1987]. We computed the average values of the realized risk premium, $F(t, T)-S(T)$, to examine the difference in risk premium for the different power markets and maturities. Table 4 reports the mean values of the risk premiums and their corresponding $t$-statistics.

The APX and EEX risk premium mean shows a decreasing pattern with 
Table 4: Realized risk premiums.

\begin{tabular}{|l|c|c|c|} 
Market & Maturity & Mean & t value \\
\hline \hline APX & M1 & 4.31 & 4.44 \\
APX & M2 & 5.58 & 4.57 \\
APX & M3 & 5.55 & 4.11 \\
APX & M4 & 4.19 & 2.78 \\
APX & M5 & 3.63 & 2.30 \\
APX & M6 & 3.38 & 1.97 \\
BELPEX & M1 & 2.36 & 2.00 \\
BELPEX & M2 & 2.55 & 1.81 \\
BELPEX & M3 & 6.83 & 3.47 \\
EEX & M1 & 1.96 & 2.00 \\
EEX & M2 & 2.25 & 2.52 \\
EEX & M3 & 1.65 & 1.74 \\
EEX & M4 & 0.79 & 0.81 \\
EEX & M5 & 0.34 & 0.33 \\
EEX & M6 & 0.23 & 0.22 \\
NPX & M1 & 2.61 & 4.30 \\
NPX & M2 & 3.84 & 3.92 \\
NPX & M3 & 4.29 & 3.40 \\
NPX & M4 & 4.74 & 3.33 \\
NPX & M5 & 4.99 & 3.32 \\
NPX & M6 & 4.91 & 3.19 \\
\hline \hline
\end{tabular}

increasing time to maturity, however the risk premium mean of Belpex and NPX increases over time. The downward slope of the average risk premium with increasing time to maturity is in line with Samuelson [1965] who shows that the return volatility of a futures contract increases as the contract approaches expiration (shorter time to maturity). A motivation for this is that, when the delivery date approaches, the information flow will increase and therefore, decreasing uncertainty will lead to higher volatility of futures contract prices. Bessembinder et al. [1996] state that the hypothesis will be supported in markets where spot prices are mean reverting. As discussed before, mean-reversion is a well-observed characteristic of electricity spot prices, therefore we can state that our results show evidence for the presence of the Samuelson effect: meaning that risk premiums in power futures prices decrease with increasing time to maturity. There is no significant evidence of the Samuelson hypothesis for the Nordic market, due to the highly seasonal variation in NPX prices.

\section{Concluding remarks}

In this paper we focus on the influence of the flexibility of power supply on electricity futures prices. We find for the Belgium, Dutch, German, 
and Nordic markets that their futures prices contain reliable information about future changes in the spot price in those markets. For the Belgium, Dutch, and German market, we find significant evidence for time-varying risk premiums, but not for the Nordic market. The latter market differs as it's power is mainly supplied from hydro plants. Although being flexible in the short run, hydro supply capacity is subject to seasonality in the long run. Flexible hydro power supply is not a substitute for storability.

We furthermore find that risk premiums increase when time brings forward contracts closer to maturity, supporting the Samuelson effect. Futures prices from the Nordic markets do not support this result, probably due to the increased uncertainty on hydro power supply capacity when time to maturity is longer.

\section{References}

H. Bessembinder and M.L. Lemmon. Equilibrium pricing and optimal hedging in electricity forward markets. Journal of Finance, 57(3):1347-1382, 2002 .

H. Bessembinder, J.F. Coughenour, P.J. Sequin, and M.M. Smoller. Is there a term structure of futures volatilities? reevaluating the samuelson hypothesis. Journal of Derivatives, 4:45-58, 1996.

A. Botterud, A.K. Bhattacharyya, and M.D. Ilic. Futures and spot prices - an analysis of the scandinavian electricity market. Proceedings of the 34th annual north american, 2002.

D.T. Breeden. Consumption risk in futures markets. Journal of Finance, page 503, 1980.

S. Douglas and J. Popova. Storage and the electricity forward premium. Energy Economics, 30(4):1712-1727, 2008.

Alexander Eydeland and Krzysztof Wolyniec. Energy and power risk management: new developments in modeling, pricing, and hedging. John Wiley \& Sons, New Jersey, U.S.A., 2003.

E.F. Fama. Spot and forward exchange rates. Journal of Monetary Economics, 14:319-338, 1984.

E.F. Fama and K.R. French. Commodity futures prices: Some evidence on forecast power, premiums, and the theory of storage. Journal of Business, 60(1):55-73, 1987.

S.E. Fleten and J. Lemming. Constructing forward price curves in electricity markets. Energy Economics, 25(5):409-424, 2003. 
D. Furio and V. Meneu. Expectations and forward risk premium in the spanish deregulated power market. Energy Policy, 38:784-793, 2010.

O. Gjolberg and T. Johnsen. Electricity futures: inventories and price relationships at nord pool. Discussion paper D-16, 2001.

T.B. Hazuka. Consumption betas and backwardation in commodity markets. Journal of Finance, 39(3):647-655, 1984.

R. Huisman. The influence of temperature on spike probability in day-ahead power markets. Energy Economics, 30:2697-2704, 2008.

R. Huisman. An introduction to models for the energy markets. Risk Books, 2009.

S.P. Kolos and E.I. Ronn. Estimating the commodity market price of risk for energy prices. Energy Economics, 30(2):621-641, 2008.

F.A. Longstaff and A. Wang. Electricity forward prices: a high-frequency empirical analysis. Journal of Finance, 59(4):1877-1900, 2004.

J. Lucia and E.S. Schwartz. Electricity prices and power derivatives: evidence from the nordic power exchange. Review of Derivatives Research, $5: 5-50,2002$.

J.J. Lucia and H. Torró. Short-term electricity futures prices: evidence on the time-varying risk premium. Working paper, 2008.

T.D. Mount, Y. Ning, and X. Cai. Predicting price spikes in electricity markets using a regime-switching model with time-varying parameters. Energy Economics, 28:62-80, 2006.

D. Pilipovic. Energy risk: valuing and managing energy derivatives. McGrawHill, 2 edition, 2007.

C. Redl, R. Haas, C. Huber, and B. Bohm. Price formation in electricity forward markets and the relevance of systematic forecast errors. Energy Economics, 31(3):356-364, 2009.

P.A. Samuelson. Proof that properly anticipated prices fluctuate randomly. Industrial Management Review, 6:41-49, 1965.

A. Bloys van Treslong and R. Huisman. A comment on: Storage and the electricity forward premium. Energy Economics, 32:321-324, 2010.

R. Weron. Market price of risk implied by asian-style electricity options and futures. Energy Economics, 30(3):1098-1115, 2008.

S. Wilkens and J. Wimschulte. The pricing of electricity futures: evidence from the european energy exchange. Journal of Futures Markets, 27(4): 387-410, 2007. 